\title{
WHAT RELATIONS CAN HOLD AMONG GOALS, AND WHY DOES IT MATTER?
}

\author{
KARIN EDVARDSSON BJÖRNBERG \\ Division of Philosophy, Royal Institute of Technology \\ ked@infra.kth.se
}

SUMMARY: Goals are often set as part of clusters of goals. On the assumption that goals are set because we want to achieve them it is interesting to study not only the conditions under which individual goals are rational (functional) but also the factors that combine to determine the rationality of a goal system. This paper argues that to be rational goal systems ought to be coherent, at least to some degree. The paper provides an analysis of goal system coherence and discusses to what extent goal conflicts are problematic from an action-guiding viewpoint.

KEY WORDS: goal-setting, rationality, coherence, operationalization, goal conflicts

RESUMEN: Muchas veces las metas se fijan como parte de grupos de metas. Bajo el supuesto de que las metas se fijan porque queremos lograrlas, resulta interesante estudiar no sólo las condiciones en las que cada meta es racional (funcional), sino también los factores que se combinan para determinar la racionalidad de un sistema de metas. Este trabajo argumenta que, para ser racionales, los sistemas de metas deben ser coherentes, o al menos deben serlo hasta cierto punto. El artículo ofrece un análisis de la coherencia de un sistema de metas y discute en qué grado los conflictos de metas son problemáticos desde el punto de vista de guiar la acción.

PALABRAS CLAVE: fijación de metas, racionalidad, coherencia, operacionalización, conflictos de metas

\section{Introduction}

Public goals and private goals are commonly parts of clusters, or systems, of goals. A government's goal to reduce unemployment may be but one among a number of political goals, ranging over fields as diverse as health care, education, environmental policy, and agriculture. In private life, a person's goal to get a good education may be only one among several goals that she has set, with the others encompassing things such as having children, becoming a successful lawyer, or becoming the owner of a beautiful beach house. In these public and private goal clusters, different relations hold among the goals. Some goals are supportive in the sense that they facilitate the achievement of other goals, while others render impossible or severely impede the realization of one another. In practice, many public and private goal systems contain goals that support one another and goals that conflict. Realizing the goal to close down a nuclear power plant could facilitate the achievement of the goal to create an 
ecologically sustainable society, while at the same time conflict with the goal to reduce unemployment. Realizing the goal to become a successful lawyer could support a person's goal to obtain a certain standing among her peers, while at the same time conflict with her goal to spend time with her friends and family.

Despite being central to individual and collective decision-making, goals have not attracted as much explicit attention in philosophy as intentions, beliefs, and values. This is somewhat puzzling, since goals function in much the same way as intentions, the coherence of goal systems is related to the coherence of belief systems, and goal conflicts have many features in common with value conflicts. Outside philosophy, goal-setting has attracted considerably more attention. In management theory and public administration, a number of studies and meta-studies have been carried out on organizational management by objectives (MBO) schemes (e.g., Rodgers and Hunter 1991; Poister and Streib 1995), and in psychology, the issue of goal-setting in relation to task motivation and performance has attracted much attention (e.g., Locke and Latham 1990).

While it is at times recognized that there are different kinds of relations among goals (e.g., Millgram and Thagard 1996; de Haas et al. 2000), the nature of those relations still remains largely unexplored. ${ }^{1}$ This is unfortunate, since having a clear grasp of the relations that exist among goals is constitutive to the efficiency of the planning process and to our understanding of goal rationality. This paper argues that goals are typically rational (functional, successful, effective) when they satisfy a set of rationality criteria for individual goals, namely precision, evaluability, attainability (approachability), and motivity (Edvardsson and Hansson 2005). ${ }^{2}$ In addition, when goals are part of goal systems the goal systems should also be coherent, at least to some degree. The paper confirms that the coherence of a goal system is influenced by the relations that hold among the goals, and identifies four such relations: operationalization, means and ends, support, and conflict. The degree to which a goal system has to be coherent to be rational is investigated, and it is concluded that even though having conflicting goals is not always downright irrational, goal conflicts are nevertheless problematic from an actionguiding (and perhaps action-motivating) viewpoint, especially when

${ }^{1}$ Of course, exceptions exist, e.g., Rosencrantz 2008.

2 In this paper, the term "rationality" is given a rather wide interpretation. Readers who prefer a more restricted usage of the term may instead use the terms "functional goals" or "successful goals" when the paper talks about "rational goals". 
there are no clear principles on the basis of which goal prioritizations can be made.

The article begins with a brief outline of goal rationality. Section 2 explains why agents set goals, and introduces the rationality criteria for individual goals. Section 3 discusses the relationship between individual goal rationality and goal system coherence, and introduces the notions of operationalization, means and ends, support, and conflict. Section 4 analyzes the relation of operationalization, section 5 the means/ends relation, and section 6 the relations of support and conflict. Section 7 returns to the issue of goal system coherence and further discusses the trouble with goal conflicts. The concluding section points out a number of philosophical issues that are in need of further investigation.

\section{Why Do We Set Goals?}

To understand how the relations that hold among goals are of importance to the rationality of goal systems, one must start out from the reason why goals are set at all. Fortunately, the reason for setting goals is fairly straightforward. Goals are typically set because the agents want to achieve the states corresponding to those goals and because the agents believe that the setting of such goals enhances the likelihood that those states will be achieved (cf. Frankfurt 1992). A goal that successfully furthers its achievement is "achievementinducing" (Edvardsson and Hansson 2005). Another way to put it is that an achievement-inducing goal performs its typical function well - the goal regulates action in a way that furthers goal achievement.

Goals typically regulate action intertemporally and interpersonally. Intertemporally, goals enable agents to plan their activities over time so that the goals are more easily reached. They function as a filter of admissibility in the sense that the agent will hesitate to consider as live options those actions that work against her goals (cf. Bratman 1999). ${ }^{3}$ For example, having adopted the goal to submit a philosophy paper on Thursday at $12 \mathrm{am}$, the agent will typically not continue deliberating about whether to spend the rest of the week climbing in a remote mountain area or to make binding appointments with a long-lost friend. In this way, the goal functions as a conductcontroller. It narrows down the scope of future deliberations to a

${ }^{3}$ A similar idea is advanced by Levi (1986), who argues that an agent's value commitments (e.g., her moral principles, professional obligations, economic interests, personal ideals, and projects) impose constraints on the ways in which feasible options are evaluated. 
limited set of options, and provides a reason for considering some of the options but not others.

Goals can also facilitate coordination of action in social contexts. ${ }^{4}$ Based on a goal, a group of agents can plan and coordinate their actions in ways that further goal achievement. This interpersonal coordination can be formal, as in the case of a football team deciding on a particular playing strategy for an upcoming game, or the coordination can be of a more informal kind, as in the case of the First World War German and French soldiers jointly but informally coordinating their trench warfare in a way that facilitated the common goal to enjoy a ceasefire during meals that were served at the same time on both sides (Axelrod 1984).

At least four properties contribute to making goals achievementinducing, namely precision, evaluability, attainability, and motivity. These criteria are called rationality criteria for individual goals (Edvardsson and Hansson 2005). The criteria can be structured according to three major dimensions that are involved in goal-based human action. The first dimension concerns what the agent knows about the goal and how close she is to it. This epistemic dimension is reflected by the rationality criteria of precision and evaluability. The second dimension concerns what the agent can do to achieve or approach the goal. This ability-related dimension is reflected by the criterion of attainability, i.e., that the goal should be possible to achieve, or at least to approach. The third dimension concerns what the agent wants to do and the ability of the goal to motivate action. This volitional dimension is expressed in the criterion of motivity.

It could be objected that the list of rationality criteria is incomplete and ought to be supplemented with additional criteria. For example, in management literature it is sometimes claimed that goals should be understandable and able to be communicated to a broad audience, which is not equivalent to being precise, and that goals should be flexible in the sense that there is a framework in force that allows for continuous revision and fine-tuning of the goals to fit changing conditions, for example, as more information and other factors come to light (Slocombe 1998).

It holds for each of the four rationality criteria that, ceteris paribus, improved satisfaction of a criterion makes a goal function

\footnotetext{
${ }^{4}$ Cf. Nozick (1993, pp. 9ff.), who argues that a person's principles may have an interpersonal function, i.e., when an agent endorses a certain principle other agents can to some extent rely upon her behaviour and themselves "perform actions whose good outcome is contingent upon the principled person's specific behaviour."
} 
better in the achievement-inducing sense. However, in some cases conflicts can exist between two or more of the criteria. Such conflicts can arise from the fact that some of the properties that make a goal action-guiding may also make the goal less motivating. Since goals are used by agents in specific contexts, factors beyond the goal itself, such as the degree to which there is general knowledge of how to reach a specific goal, will determine the extent to which the goal's action-guiding or action-motivating properties need to be given priority to advance goal achievement.

\section{Goal System Rationality}

When a goal is part of a goal system (set of goals), it is of interest to determine not only the rationality of the individual goal but also that of the goal system. Ideally, the goal system should be as achievementinducing as possible, i.e., the goals should be set in a way that brings us as close as possible to where we want to be. To do so, the goals must not only satisfy the rationality criteria for individual goals. They must also be related to one another in a way that allows for efficient coordination of action -in other words, the goal system ought to be coherent.

Goal systems are coherent much in the same way as belief systems. In the basic sense, "coherence" refers to some property that makes the elements (e.g., propositions, rules, principles, goals) of a set fit together (Hansson 2006). Since this "fitting together" comes in degrees, sets of elements can be more or less coherent (Brendel 1999). As was argued by BonJour (1985), the degree of coherence belonging to a particular set is determined by the relations that exist among the elements in the set. Generally, a high degree of coherence among the elements is sought after, and methods of computing coherence have been proposed to that end (Thagard 2000).

When the elements in a set consist of goals, the coherence of the set is made up of at least two types of goal relations: support relations (S-relations) and relations of conflict (C-relations). An S-relation exists between two goals when the achievement of one goal facilitates the achievement of the other goal, or when the goals facilitate the achievement of each other. Another way to put it is that actions that are performed to achieve one goal also bring the agent closer to the other goal. Some S-relations are also means-ends relations (M/Erelations). An M/E-relation exists between two goals when one of the goals is set with the purpose of contributing to the achievement of 
the other. A C-relation exists between two goals when it is impossible or difficult to achieve both goals, i.e., when actions that are performed to achieve one goal render it more difficult to reach the other goal.

A fourth relation that could affect the coherence of a goal system is the relation of operationalization (O-relation). An O-relation exists between two goals when one of the goals specifies the other by providing information about either possible realizations of that goal or how the goal is to be pursued. Operationalization is a means whereby primary, or overarching, goals can be made more actionguiding and action-motivating.

Both single goal rationality and coherence are conducive to the achievement-inducing capacity of a goal system. Individual goal rationality may not be enough for a goal system to be achievement-inducing because individual goals can be very precise, evaluable, and so on, and still conflict with one another. ${ }^{5}$ When this is the case, each individual goal will be action-guiding. However, taken together the goals will guide action in opposite directions. Coherence, or at least consistency among the goals, could evade this problem and allow for coordinated planning.

The reason why coherence may not be enough for a goal system to be achievement-inducing is that coherence, or at least the absence of inconsistency, could be obtained by setting very vague or ambiguous goals, or by setting goals that are very easy to attain in the sense that they would have been achieved even if the agent had not adopted them. The problem with vague and ambiguous goals is of course that they provide bad action guidance. Goals that are very easy to achieve in the sense described above are problematic, since they seem to miss the point of goal-setting altogether. As goals, they are rather meaningless - they do not represent any real commitments and therefore fail to exercise their typical function of bringing agents closer to where they want to be.

From an internal perspective, coherence is merely about fitting a set of elements together. Judgments of coherence are, however, often informed by factors external to the structure of a particular goal system, such as the agent's value commitments or priorities among the goals (Thagard and Millgram 1995). Given that some

\footnotetext{
${ }^{5}$ In some interpretations, the criterion of attainability already prevents such goal conflicts, since the attainability of an individual goal is usually partly determined on the basis of its relations to other goals. For example, a goal whose realization requires half a country's GNP is attainable only in a very restricted sense.
} 
of the agent's goals are considered more important than others, a high degree of coherence among those goals is therefore usually more important than a high degree of coherence among some less important goals.

Before continuing with the analysis, it should be noted that the rational goal model described here is simplified and that the effectiveness of goal systems also depends on a number of factors that are exogenous to the goals. In the public sector, rational goal-setting must, for example, be understood in terms of the organizational context in which the goals are set - contexts that are to a large part influenced by organizational norms, interests, and routines (Simon 1947). Goals are often formulated at a "higher" level in the administrative chain and operationalized by agents who are situated at "lower" administrative levels. In such administrative settings, the success of the goals partly depends on whether there is a clear framework for communication between key agents located at different levels in the administrative chain and whether the division of responsibilities for operationalization and implementation is sufficiently specified (Wibeck et al. 2006).

\section{The Relation of Operationalization}

Public policy documents often point out that goals should be operational and that they can be operationalized through the adoption of sub-goals, or interim targets. This section defines the O-relation, explains in what way the O-relation influences the rationality of goal systems, and discusses what a good, or effective, operationalization is.

The O-relation exists between primary goals and sub-goals. It could tentatively be defined in the following way: A primary goal $A$ is operationalized by one or several sub-goals $B_{1}, \ldots, B_{n}$ when each of the sub-goals specifies $A$ by contributing information about i) possible realizations of $A$ or ii) how $A$ is to be pursued. The definition seizes upon the idea that the contribution of information is central to the relation of operationalization. Two kinds of specifications are recognized: those that provide information about the goal itself and those that provide information about means to reach the goal. An example of the former kind of specification is the sub-goal of the United Nations millennium development goal Improve maternal health, which states that the maternal mortality ratio should be reduced by three quarters. An example of the latter is a sub-goal of the goal of gender equality in working life, which states that by 2010 all business firms 
with more than ten employees should have a gender equality plan in force.

When a goal is operationalized, it can more easily guide action, since it is usually easier to plan on the basis of more detailed information. In institutional settings, where operationalization most frequently occurs, primary goals are often vague and in need of clarification to function as bases for selecting adequate means. However, operationalization can also be used to make primary goals more action-motivating. By specifying a primary goal as described above, the sub-goals make the primary goal psychologically more "real" to the agent, thus helping to prevent "procrastination and premature discouragement" (Locke and Latham 1990).

At this point, it could be questioned why we should construct goal systems in which primary goals are operationalized by more detailed sub-goals at all. Why not adopt goals that satisfy the rationality criteria for individual goals and skip the practice of linking primary goals and sub-goals through the relation of operationalization? The reason is that it can be difficult to adopt individual goals that are both action-guiding and action-motivating. In some situations, goals can be precise enough to guide action but do not inspire agents to take the actions necessary to achieve the goal. One way of balancing the criteria to optimize goal achievement is to adopt goal systems in which goals are set on different levels to supplement each other (Edvardsson and Hansson 2005). Adopting precise and evaluable subgoals that operationalize visionary and motivating primary goals is a way of confirming that the goal system guides and motivates action.

However, not every operationalization contributes to making a goal system more action-guiding or motivating. In order for an operationalization to be successful, a number of requirements have to be satisfied, namely the requirements of usefulness, relevance, consistency, comprehensiveness, and non-redundancy.

To illustrate the requirement of usefulness, consider the following example. Sarah's goal is to bathe in a Scottish burn at least once in her life $(A)$. In order to reach the goal, she adopts the sub-goal to get to a Scottish burn $(B)$. According to the definition above, $B$ constitutes an operationalization of $A$, since $B$ specifies $A$ by providing information about how to pursue it. To call this an operationalization, however, seems somewhat misleading, since the information provided by $B$ appears to be redundant, i.e., the information provided by the conjunction of $A$ and $B$ is no more useful, or action-guiding, than the information provided by $A$ alone. The reason for this is of course 
that bathing in a Scottish burn implies getting to such a burn somehow. In light of this, it could be argued that to be meaningful an operationalizing goal should convey information of a certain quality, say, so that the information provided by the conjunction of $A$ and $B$ is more detailed (cf. Keeney and Raiffa 1976) or more useful than the information provided by $A$ alone. ${ }^{6}$

However, satisfying the requirement of usefulness does not seem to exclude operationalizations similar to the following. The overall goal of the Metropolitan Police Department is to solve more violent crimes $(A)$. The goal is operationalized through the sub-goal of increasing the percentage of solved sex crimes $(B)$, which in turn is operationalized through the further sub-goal of removing from the cause-list those sex crimes that have not been solved within three weeks $(C)$. In this situation, $B$ is a specification of $A$, and $C$ is a specification of $B$. In addition, the information provided by the conjunction of $\mathrm{A}$ and $\mathrm{B}$ is more action-guiding than the information provided by $A$ alone, and the information provided by the conjunction of $B$ and $C$ is more action-guiding than the information provided by $B$ alone. Nevertheless, this way of operationalizing the goal to solve more violent crimes is flawed. One does not get closer to the goal of solving more violent crimes by achieving the sub-goal of removing from the cause-list those sex crimes that have not been solved within three weeks. In addition, it could therefore be argued that for a sub-goal to constitute an appropriate operationalization of a primary goal, the realization of the sub-goal should in some way be relevant to the realization of the primary goal, for example, because realization of the sub-goal contributes to the goal's achievement. If this is correct, there is an interesting relationship between the O-relation and the S-relation that deserves further attention.

In practice, primary goals are often specified through subdivision into sets of sub-goals. When a set of sub-goals specifies a primary goal the set of sub-goals should not only provide non-trivial information about the contents of the goal or the means to reach it. To be actionguiding (and perhaps action-motivating), the set of sub-goals should also typically satisfy the requirement of consistency. For if the subgoals specify inconsistent means of reaching the primary goal, it is impossible to determine what should be done to reach the goal.

${ }^{6}$ The problem is of course to explain what it means to say that the information that the conjunction of two goals provides is more useful than the information provided by one of the goals. It could, for example, be taken to mean that the provided information renders the goals more action-guiding in the sense that the selection of means is easier to perform. 
The requirement that goals ought to be consistent is further discussed in section 7 .

It could be argued that to be rational a set of sub-goals should also satisfy a requirement of comprehensiveness, i.e., the sub-goals should cover the most important aspects of the primary goal, or what people regularly mean when they refer to the primary goal. The problem with sets of sub-goals that are not comprehensive is that by achieving the sub-goals one does not get sufficiently close to the primary goal. In practice, however, the requirement of comprehensiveness is seldom fully satisfied. As an example, it has been argued that the sub-goals of the Swedish environmental quality objective $A$ good built environment, which cover aspects such as noise reduction, the extraction of gravel, waste management, the protection of cultural heritage, and the quality of the indoor environment, do not fully capture what people ordinarily refer to when they talk about a good built environment (SEOC 2003). Among the aspects that are not covered by today's sub-goals, but are nevertheless part of what most people require of a good built environment, are security and accessibility.

However, satisfying the requirement of comprehensiveness by adding a large number of sub-goals hardly renders the goal system more functional. By doing so, the meaning of the primary goal is perhaps to a larger extent covered by the sub-goals, but this does not imply that the goal system is made more functional. On the contrary, after a certain point the complexity involved may in fact render the goal system less functional. ${ }^{7}$ Therefore, although sub-goals should be set so that they cover the most important aspects of a primary goal, a balance must be struck concerning the actual level of specification, or detail, strived for. For this purpose, it is helpful to make sure that the set of sub-goals satisfies the requirement of non-redundancy, i.e., that two or more sub-goals do not specify the same part or aspect of the goal (cf. Keeney and Raiffa 1976). The requirement of nonredundancy helps to reduce the number of goals in a goal system and contributes to making the system lucid.

\section{The Means-Ends Relation}

The M/E-relation is a particular kind of support relation that exists between primary goals and sub-goals. When a sub-goal $(B)$ is a means to some primary goal $(A), B$ is set with the purpose of

${ }^{7}$ For a discussion of the idea that goal systems should not contain a large number of goals, see Mali 1972 and Latham 2003. 
contributing to the realization of $A$. The belief that $B$ is causally connected with $A$, so that the achievement of $B$ contributes to the achievement of $A$, is part of the reason why $B$ is adopted. This does not amount to saying that $B$ is nothing but a means or that $B$ is only instrumentally valued, since $B$ can also be an end that is valued for its own sake.

The M/E-relation is a support relation, but not every support relation is an M/E-relation. A goal can support the achievement of another goal without being a means to that goal. To illustrate this point, consider the following example. The government's goal is to protect the biological diversity of the North Sea $(A)$. To reach $A$, the government adopts a number of sub-goals that are means toward the achievement of $A$. One of the sub-goals is to draw up a series of action programs for endangered marine species and fish stocks that are in need of targeted measures $(B)$. As things turn out, $B$ can be achieved only by employing a number of highly specialized marine biologists, something that contributes to the achievement of another governmental goal, namely the goal to lower unemployment of professionals $(C)$. In this situation, $B$ is adopted as a means to support $A$ and not $C$, but as things turn out, the realization of $B$ also supports the achievement of $C$.

According to the standard account of means and ends, ends are decided on first, and then means are selected on the basis of how well they contribute to realizing the ends in question. Translated into a goal-setting context, this means that primary goals are agreed on first and are then top-down translated into sub-goals at different management levels. However, the standard account of means and ends corresponds badly with how goals and sub-goals are usually related to one another in practice. It is perhaps largely correct in cases where primary goals are already fixed and understood, but this is seldom the case. Instead, primary goals are often vague and poorly understood until they are operationalized by one or several sub-goals. In those situations, the sub-goals not only facilitate the achievement of their primary goals but also convey meaning to the primary goals. Therefore, the relationship between primary goals and sub-goals could be described as not merely instrumental but also constitutive.

The relationship between means and ends is also ambiguous in the sense that employing a means can create new ends and values. In scientific and technological contexts, tricky problems are sometimes solved in novel ways, for example, by inventing artefacts that not only contribute to achieving a particular problem-solving goal but 
also produce new goals and values (Airaksinen and Kaalikoski 1994). ${ }^{8}$ The invention of a new genetic technology could be a way of solving the goal to reduce the occurrence of a particular genetic disease, but it could also help to form new goals and values related to the production and spread of biological weapons.

In public policy situations, the application of a particular social or economic instrument is rarely just instrumental. It also affects the way agents value public policy goals and can even cause agents to pursue new goals that would not have been considered if other instruments had been chosen (Stewart 1995). As an example, introducing a state-based "defined-contribution" pension system (e.g., an insurance system that requires citizens to invest a certain percentage of their income in funds) to make future pensioners better off in economic terms could alter the preferences, social values, and goals of those citizens. The left wing has argued that the introduction of such old-age insurance systems is in fact a way of creating an "investment culture" that links the perceived interests of tens of millions of workers to the interests of finance capital, and is ultimately a way of marketing the values of neoliberalism (Harmes 2001).

\section{The Relations of Support and Conflict}

An S-relation exists between two goals when the achievement of one of the goals furthers the achievement of the other, or when the goals further the achievement of each other. ${ }^{9}$ A C-relation exists between two goals when it is difficult or even impossible to achieve both goals, i.e., when actions that are performed to achieve one goal render it more difficult to reach some other goal. ${ }^{10}$ There are internal and external S/C-relations. Internal S/C-relations exist among goals held by one and the same agent, while external $\mathrm{S} / \mathrm{C}$-relations exist among

${ }^{8} \mathrm{I}$ am indebted to an anonymous referee, who pointed this out to me.

${ }^{9}$ An alternative way of defining the S-relation is in probabilistic terms: if $A$ supports the achievement of $B$, then the probability that $B$ will be achieved given that $A$ has been achieved is greater than the prior, or unconditional, probability that $B$ will be achieved $[p(B \mid A)>p(B)]$. Using the notion of conditional probability to define the S-relation has the advantage of making it possible to distinguish between degrees of support, at least in principle. However, it could also entail some difficulties. It has, for example, been argued that under some circumstances an event $A$ can cause an event $B$ while at the same time lower the probability of $B$, for example, by lowering the probability of other more efficient causes (Hesslow 1976).

${ }^{10}$ The fact that goal conflicts come in varying degrees of strength makes the notion of conditional probability potentially useful in defining also the C-relation. 
goals held by different agents (Wilensky 1983). S/C-relations are usually binary, but there are exceptions. Two goals in combination $\{A$, $B$ \} can facilitate the achievement of a third goal $C$, although neither $A$ nor $B$ in isolation facilitates the achievement of $C$. Moreover, a set of goals $\{A, B, C\}$ can include a goal conflict, although each proper subset $\{A, B\},\{B, C\}$, and $\{A, C\}$ is free from such conflict. The following discussion focuses on binary $\mathrm{S} / \mathrm{C}$-relations.

From a planning perspective, S-relations are beneficial, since they provide an opportunity to achieve goals more efficiently. This holds for internal and external S-relations. If an agent has two goals that support each other's achievement, then she can act in a way that serves both goals at once. Similarly, if two agents have goals that support the achievement of each other, the agents can allocate resources and in other ways coordinate their actions efficiently. C-relations are usually problematic, since inconsistent goals tend to be more difficult - expensive, time-consuming, or otherwise - to achieve. This holds for internal and external C-relations.

Some goals are logically or analytically related to each other. A logical or analytical S-relation exists between two goals when there is no possible world in which one of the goals is achieved while the other is not. As an example, consider the relationship between the goal to remain a bachelor throughout the year and the goal not to marry until next year. Achieving one of the goals means that the other goal is automatically achieved. A logical or analytical C-relation exists between two goals when there is no possible world in which the goals are simultaneously achieved. As an example, consider the conflict that exists between the goal to drink ten glasses of water every day and the goal to abstain from drinking $\mathrm{H}_{2} \mathrm{O}$.

For obvious reasons, internal logical and analytical S/C-relations are rare in practice. Agents simply do not adopt goals that are logically or analytically connected to each other in these ways. However, logical or analytical S/C-relations can certainly occur between goals that are adopted by two different agents. As an example, Hamish's goal to remain a bachelor until next year conflicts with his mother's goal to marry him off before the end of the year. More interestingly, goals that are adopted by parts of the same organization (such as a government) can also be logically or analytically inconsistent. As an example, the goal of the Swedish National Food Administration to lower the temperature in premises where food is handled from $8{ }^{\circ} \mathrm{C}$ to $4{ }^{\circ} \mathrm{C}$ for sanitary reasons conflicts with the goal of the Swedish Work Environment Authority to raise the tempera- 
ture in premises where food is handled from $8{ }^{\circ} \mathrm{C}$ to $12{ }^{\circ} \mathrm{C}$ to protect the health of the workers (Esping 1977).

Most of the S/C-relations that occur in real life are not logical or analytical but contingent in the sense that different circumstances contribute to creating an S/C-relation between the goals. The circumstances can be systematized into at least three categories: (i) the amount of resources available, (ii) the laws and traditions currently in force, and (iii) the presence of general factual influencers. Obviously, general factual influencers cover a wide spectrum of circumstances, and further distinctions can therefore probably be introduced to refine this category.

The fact that resources can influence the relationship between goals is perhaps most evident in goal conflicts. Stuart's goal to buy a lavish Oriental couch conflicts with his goal to pay next month's rent, not because buying the couch and paying the rent represent inconsistent states of affairs per se, but because they draw on a common resource of which there is a shortage, in this case money. Financial means is not the only resource that contributes to creating goal conflicts, but conflicts of this kind are certainly among the most common ones in practice.

In a similar fashion, resources can contribute to creating S-relations among goals. This happens when the achievement of one goal creates a resource - financial or of some other kind - that can be used to achieve another goal. As an example, achievement of the goal to reduce unemployment generates taxation revenues that can be used to promote other social goals.

Sometimes, laws and traditions contribute to creating goal conflicts. Due to the rules currently in force in the Roman Catholic Church the goals to be a cardinal and to be married conflict. However, they do not conflict because they both depend on some resource of which there is a scarcity. Nor are they logically or analytically inconsistent, since they could very well be achieved in a world where the teachings of the Roman Catholic Church allowed for cardinals to be married. Analogously, laws and traditions can help to create Srelations among goals. As an example, many jurisdictions contribute to creating an S-relation between the goals to get married and to secure the future financial solidity of one's partner.

Some goals conflict due to circumstances that cannot be systematized into either of the two categories discussed above. These circumstances are instead referred to as general factual influencers. The goal to be palpably intoxicated twenty-four hours a day conflicts with 
the goal of becoming a skilful violinist, not because they require a common resource of which there is a shortage or because there are legal rules prohibiting drunk persons from being excellent musicians, but because we humans are constituted so that being drunk effectively prevents us from becoming skilful violinists.

Contingent goal conflicts need not be less dramatic than logical and analytical goal conflicts. Goal conflicts that arise due to lack of resources can be very difficult to solve in practice, since reasonable trade-offs are not always readily available. A council that has enough money to fund either a football field or an ice-hockey rink cannot compromise and spend half the sum on a field and half the sum on a rink. In a similar fashion, no reasonable trade-offs can be made between the goals to be a cardinal in the Roman Catholic Church and to be married. As in the case of logical and analytical goal conflicts, conflicts of this kind are "hard". Arguments can be put forward to defend either goal, but at the end of the day, the decision maker must choose which of the goals to invest in. Fortunately, many goal conflicts that occur in real life are of a "softer", or less dramatic, kind. Spending money to improve the much neglected oldage care makes it more difficult to pursue the goal of renovating the municipality's playgrounds, but local decision makers can still reasonably choose to spend a smaller sum on the playgrounds and a larger sum on the old-age care.

\section{Is It Irrational to Adopt Conflicting Goals?}

How coherent, then, must an agent's goals be to be rational? It is important to notice that both S-relations and C-relations constitute the coherence of a goal system. Hence, absence of conflict is not enough for a goal system to have a high degree of coherence. However, it is possible that what is most important for a goal system to be action-guiding and motivating (and hence achievement-inducing) is that it contains few C-relations. The fact that it contains many S-relations could increase the goal system's degree of coherence, but this increase need not correspond to a similar increase in the degree to which the goal system is achievement-inducing. Therefore, the following discussion will focus on C-relations.

On an individual level, having conflicting goals could be criticized for being, if not downright irrational, then at least unsound. The strength of the argument depends on whether goals are considered on a par with intentions, or if the goals are instead considered comparable to desires. Intentions and desires are similar in the sense 
that having them represents a mental state. Having an intention or a desire means that the agent has a certain disposition, or pro-attitude, toward actions of some sort, namely those actions that she believes will bring her closer to fulfilling her intention or desire (Bratman 1999; McCann 1991). As an example, when I have an intention or a desire to visit the city hall tonight, this means that I have a certain disposition, or pro-attitude, toward actions that will bring me closer to visiting the city hall tonight. However, the relationship between my having this disposition and actually letting it influence my actions is of a stronger kind for intentions than for desires. This explains why it makes sense to say that "I desire to visit the city hall tonight, but I won't (or can't) do it", while it does not under normal circumstances make sense to say that "I intend to visit the city hall tonight, but I won't (or can't) do it". Intentions involve a stronger commitment to future action than desires; intentions are not merely conduct-influencing but also conduct-controlling.

Goals function much in the same way as intentions; goals are typically adopted to regulate action toward their achievement, and by adopting goals, agents typically commit themselves to future action of a certain kind. Consequently, goal conflicts are more problematic than they would have been if goals had instead been considered more similar to desires. An agent who has conflicting desires can, however, still have a reason to revise them, since having inconsistent desires tends to make agents frustrated. ${ }^{11}$

However, that goal conflicts are problematic from an action-regulating viewpoint is not equivalent to saying that it is always irrational to have goals that conflict with one another. At least three arguments can be forwarded to defend this idea - epistemic, empirical, and normative arguments.

From an epistemic viewpoint, allowing for a certain flexibility when it comes to goal conflicts can be wise considering that it can be difficult to know in advance whether one's goals are consistent or not. Apparently consistent goals that are adopted at one point in time can turn out to conflict as conditions external to the goals change. Similarly, goals that were previously in conflict can become consistent with one another as new means of goal realization are discovered.

In practice, goal conflicts are more or less considered a fact of life, both among individuals and within institutions (cf. Berlin 1988). In

\footnotetext{
${ }^{11}$ Richardson (1997) argues that although the demand for strong coherence among one's desires and ends is not built into the notion of happiness, the pursuit of happiness is nevertheless greatly advanced by some systematization of one's ends.
} 
the public sector, economic goals conflict with social security goals, environmental goals with transportation policy goals, and so on, and it is not considered realistic to create goal systems that are entirely free from conflict. That institutions habitually adopt conflicting goals is an empirical fact that is also recognized in public administration research. It has even caused some researchers to propose models of organizational choice that are built on the assumption that organizations are seen as "organized anarchies" that are essentially characterized by unclear and inconsistent goals. The "garbage can" model of organizational choice is an example of such a model (Cohen et al. 1972).

From a normative perspective, the creation of goal systems that are entirely free of conflicts need not even be desirable. To create goal systems that are free of conflict, one would have to systematically avoid goals that represent any real commitment, since there is always a risk that they will conflict with one another. ${ }^{12}$ As was pointed out earlier, the problem is that such goals are rather pointless. A far more fruitful way is to prudently adopt those goals that one desires to achieve, while recognizing that potential goal conflicts will probably have negative effects on the planning and coordination of action, and then try to find methods of solving the conflicts that arise along the way. In a social context, and perhaps also on an individual basis, allowing for a certain degree of conflict among one's goals could even be beneficial in the sense that it could spur reflections and discussions concerning goal implementation, prioritization, and the weighing of values, and inspire agents to find novel means to reach the goals in question.

In institutional settings, goal conflicts can make it more difficult to coordinate action among agents. To avoid wasting resources and allow for the efficient coordination of action, information about the relative weight of the goals is often useful, for example, in the form of established rules of thumb or other weighing principles. However, in many goal conflicts in institutional settings, such as the public sector, such information is lacking. Goals are regularly set on a national government level, and implementation is transferred to regional and

${ }^{12}$ Analogous arguments have been put forward in value theory. For example, Hansson 1998 argues that a world without moral dilemmas is not desirable. The reason for this is that strategies that reduce the incidence of moral dilemmas tend to have side effects that are not worth the price. To avoid dilemmas as much as possible, agents would have to systematically avoid commitments to other people, since virtually any such commitment increases the risk that agents will later find themselves in a dilemma. However, a community of commitment-avoiders is not much of a community. 
local authorities with no accompanying principles on how to prioritize the goals. The effect is that goal implementation often becomes fragmentized and ill-coordinated, at least in the absence of a continuous dialogue among the implementing authorities concerning goal prioritization.

The lack of guiding principles is particularly troublesome when it comes to "hard" goal conflicts, i.e., when it is impossible to make any reasonable trade-offs between the goals in question. However, "soft" goal conflicts can also benefit from principles that guide the prioritization of values. The pivotal role of guiding principles points to an alternative way of defining goal system coherence. Instead of defining goal system coherence solely in terms of the relationships that exist among the goals in the system as described above, goal system coherence could be defined in terms of the relationships that exist among the goals and the available principles of goal priorities. A goal system that is coherent in this modified sense will in most cases have the capacity to guide action, and, hence, be rational, even though it contains some goal conflicts.

\section{Conclusions}

Although there are strong pragmatic reasons for systematizing one's ends so that goal conflicts are avoided, the argument that it is necessarily irrational to have conflicting goals cannot be defended. However, to provide a more elaborate theory of goal system rationality, several philosophical issues are in need of clarification. In this article, only the more basic task of identifying and analyzing the O-relation, M/E-relation, S- and C-relations has been performed. To give a fuller account of goal system coherence, the relationships that hold among those relations need to be investigated. Furthermore, a number of more specific issues regarding the four goal relations should be addressed. Regarding the O-relation, the identified requirements of successful operationalization are in need of refinement, and regarding the C-relation, additional distinctions should be elaborated with the aim of refining the category of general factual influencers. Finally, further studies into epistemic and deliberative coherence are needed to give a more comprehensive account of goal system coherence and the relationship that holds between goal system coherence on the one hand and goal system rationality on the other. ${ }^{13}$

${ }^{13}$ I would like to thank Professor Sven Ove Hansson, Professor Erik Carlson, Holger Rosencrantz, and two anonymous referees for their helpful comments and suggestions. This final version remains my responsibility. 


\section{REFERENCES}

Airaksinen, Timo and Katri Kaalikoski, 1994, "Instrumental Rationality", Protosoziologie, vol. 6, pp. 151-159.

Axelrod, Robert, 1984, The Evolution of Co-Operation, Penguin Books, London.

Berlin, Isaiah, 1988, "On the Pursuit of the Ideal", The New York Review of Books, vol. 35, no. 4, pp. 11-18.

BonJour, Laurence, 1985, The Structure of Empirical Knowledge, Harvard University Press, Cambridge/London.

Bratman, Michael E., 1999, Intentions, Plans, and Practical Reason, CSLI Publications, Stanford.

Brendel, Elke, 1999, "Coherence Theory of Knowledge: A Gradational Account", Erkenntnis, vol. 50, pp. 293-307.

Cohen, Michael D., James G. March and Johan P. Olsen, 1972, "A GarbageCan Model of Organizational Choice", Administrative Science Quarterly, vol. 17, pp. 1-5.

De Haas, Marco, Jen Algera, Harrie F.J.M. van Tuijl and Jacqueline Meulman, 2000, "Macro and Micro Goal Setting: In Search of Coherence", Applied Psychology: An International Review, vol. 49, no. 3, pp. 579595.

Edvardsson, Karin and Sven Ove Hansson, 2005, "When Is a Goal Rational?", Social Choice and Welfare, vol. 24, pp. 343-361.

Esping, Hans, 1977, Förvaltning - förändring — framtid, Sekretariatet för framtidsstudier, Liber, Stockholm.

Frankfurt, Harry, 1992, "On the Usefulness of Final Ends", Iyyun - The Jerusalem Philosophical Quarterly, vol. 41, pp. 3-19.

Hansson, Sven Ove, 2006, "Coherence in Epistemology and Belief Revision", Philosophical Studies, vol. 128, pp. 93-108.

—_ 1998, "Should We Avoid Moral Dilemmas?", The Journal of Value Inquiry, vol. 32, pp. 407-416.

Harmes, Adam, 2001, "Mass Investment Culture", New Left Review, vol. 9, pp. 103-124.

Hesslow, Germund, 1976, "Discussion: Two Notes on the Probabilistic Approach to Causality", Philosophy of Science, vol. 43, pp. 290-292.

Keeney, Ralph L. and Howard Raiffa, 1976, Decisions with Multiple Objectives: Preferences and Value Tradeoffs, John Wiley and Sons, New York.

Latham, Gary P., 2003, "Goal Setting: A Five-Step Approach to Behaviour Change", Organizational Dynamics, vol. 32, no. 3, pp. 309-318.

Levi, Isaac, 1986, Hard Choices: Decision Making under Unresolved Conflict, Cambridge University Press, Cambridge.

Locke, Edwin A. and Gary P. Latham, 1990, A Theory of Goal Setting and Task Performance, Prentice Hall, Englewood Cliffs. 
Mali, Paul, 1972, Managing by Objectives: An Operating Guide to Faster and More Profitable Results, John Wiley and Sons, New York.

McCann, Hugh, 1991, "Settled Objectives and Rational Constraints", American Philosophical Quarterly, vol. 28, pp. 25-36.

Millgram, Elijah and Paul Thagard, 1996, "Deliberative Coherence", Synthese, vol. 108, pp. 63-88.

Nozick, Robert, 1993, The Nature of Rationality, Princeton University Press, Princeton.

Poister, Theodore H. and Gregory Streib, 1995, "MBO in Municipal Government: Variations on a Traditional Management Tool", Public Administration Review, vol. 55, no. 1, pp. 48-56.

Richardson, Henry S., 1997, Practical Reasoning about Final Ends, Cambridge University Press, Cambridge.

Rodgers, Robert and John E. Hunter, 1991, "Impact of Management by Objectives on Organizational Productivity", Journal of Applied Psychology, vol. 76, no. 2, pp. 322-336.

Rosencrantz, Holger, 2008, "Properties of Goal Systems: Consistency, Conflict, and Coherence", Studia Logica, vol. 89, pp. 37-58.

SEOC (The Swedish Environmental Objectives Council), 2003, Sweden's Environmental Objectives: Will the Interim Targets be Achieved?, SEOC, Stockholm.

Simon, Herbert A., 1947, Administrative Behaviour: A Study of DecisionMaking Processes in Administrative Organizations, Free Press, New York.

Slocombe, Scott D., 1998, "Defining Goals and Criteria for Ecosystem-Based Management", Environmental Management, vol. 22, no. 4, pp. 483-493.

Stewart, Hamish, 1995, "A Critique of Instrumental Reason in Economics", Economics and Philosophy, vol. 11, pp. 57-83.

Thagard, Paul, 2000, Coherence in Thought and Action, MIT Press, Cambridge, Mass.

Thagard, Paul and Elijah Millgram, 1995, "Inference to the Best Plan: A Coherence Theory of Decision", in A. Ram and D. B. Leake (eds.), GoalDriven Learning, MIT Press, Cambridge, Mass., pp. 439-454.

Wibeck, Victoria, Madelaine Johansson, Anna Larsson and Gunilla Öberg, 2006, "Communicative Aspects of Environmental Management by Objectives: Examples from the Swedish Context", Environmental Management, vol. 37, no. 4, pp. 461-469.

Wilensky, Robert, 1983, Planning and Understanding: A Computational Approach to Human Reasoning, Addison-Wesley, Reading, Mass.

Received: January 5, 2006; revised: June 7, 2008; accepted: October 1, 2008. 